\title{
Research Paper: Effectiveness of Resource Management Strategies and Achievement Goals Orientation in Predicting Academic Achievement Among Students With Hearing Impairment
}

\author{
*Seyed Somayeh Jalil-Abkenar ${ }^{1}$, Mohammad Ashori ${ }^{1}$, Saeed Hasanzadeh ${ }^{1}$
}

1. Department of Psychology and Exceptional Children Education, Faculty of Psychology and Education, University of Tehran, Tehran, Iran.

Received: 5 Sep. 2016 Accepted: 23 Nov. 2016

Keywords:

Resources management strategies, Achievement goals orientation, Hearing impairment
Citation: Jalil-Abkenar SS, Ashori M, Hasanzadeh S. [Relationship of the Resources Management Strategies and Achievement Goals Orientation in Predicting Academic Achievement on the Students With Hearing-impaired (Persian)]. Journal of Rehabilitation. 2017; 17(4):280-289. http://dx.doi.org/ 10.21859/jrehab-1704280

http://dx.doi.org/ 10.21859/jrehab-1704280

\section{ABSTRACT}

Objective The purpose of the present research was to investigate the relationship of the resources management strategies and achievement goals orientation in predicting academic achievement in students with hearing impairment.

Materials \& Methods The present research is a descriptive-analytical correlation study. The study population included students with hearing impairment who were aged 15-18 years. Eighty students (46 boys and 34 girls) were selected by convenient sampling method from Tehran province. The instruments of present research were resources management strategies questionnaire and achievement goals orientation questionnaire-revised. Data were analyzed by using mean, standard deviation, correlation coefficient, and stepwise regression along with SPSS (version 19).

Results The normality of variables was tested. The Kolmogorov-Smirnov test showed that all variables were normal. The findings showed that resource management strategies (effort regulation and helpseeking) and achievement goals orientation (mastery approach goal and performance avoidance) have a positive and significant relationship with academic achievement $(\mathrm{P}<0.05)$. Mastery approach, effort regulation, help seeking and performance avoidance goal predicted 0.53 percent of the variance in academic achievement $(\mathrm{P}<0.05)$, and mastery approach goal had the most contribution to the prediction of academic achievement $(\mathrm{P}<0.001)$.

Conclusion Variables such as resource management strategies and achievement goals orientation have a crucial role in predicting academic achievement in students with hearing impairment.

\section{* Corresponding Author:}

Seyed Somayeh Jalil-Abkenar, PhD Candidate

Address: Department of Psychology and Exceptional Children Education, Faculty of Psychology \& Education, Jalal Al-e-Ahmad Ave, Chamran Highway, Tehran, Iran.

Tel: +98 (21) 36728780

E-Mail: jalili.abkenar@gmail.com 


\title{
ارتباط راهبردهاى مديريت منابع وجهت تَيرى هدفهاى ييشرفت در ييشبينى ييشرفت تحصيلى

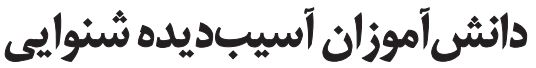

\author{
"سيدهسميه جليل آبكنار'، محمد عاشورى'، سعيد حسنزاده' \\ 1- كروه روانشناسى و آموزش كودكان استثنايیى، دانشكدة روانشاسى و علوم تربيتى، دانشعاه تهران، تهران، ايران.
}

\begin{abstract}
حكSد

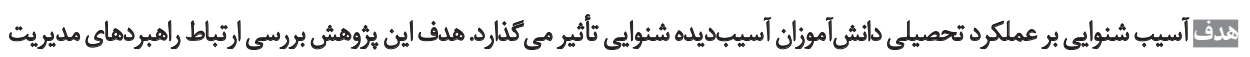

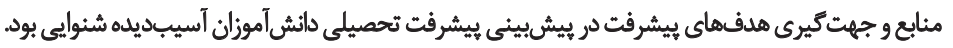

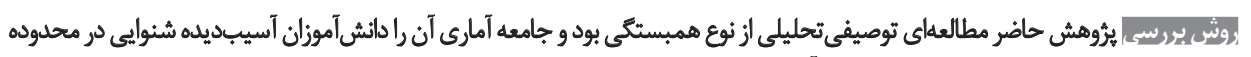

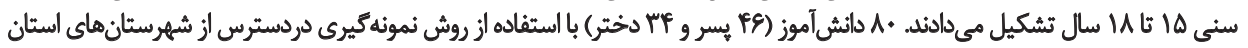

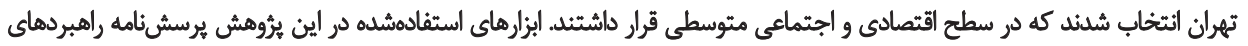

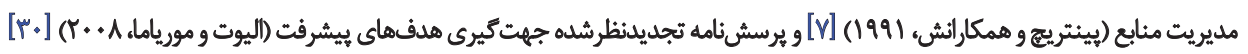

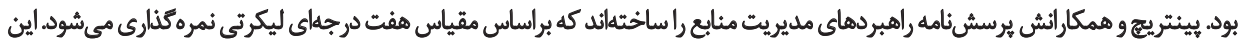

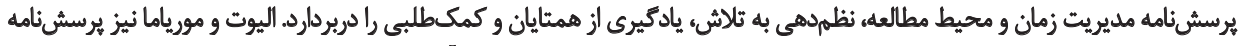

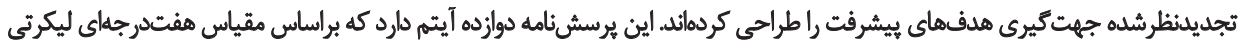

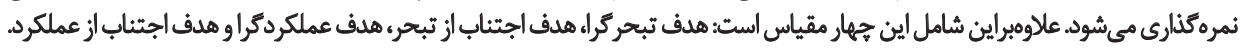

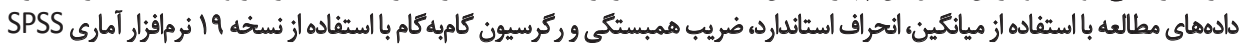
تجزيهوتحليلشد.

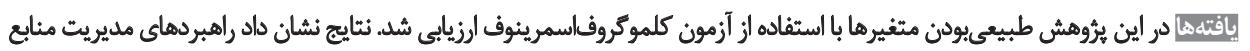

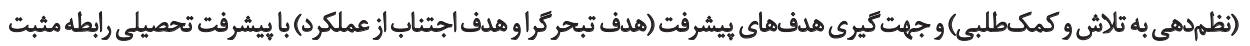

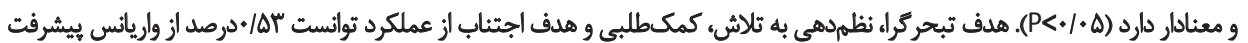

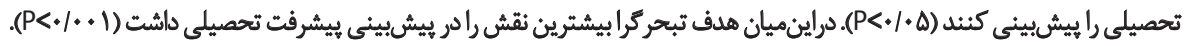

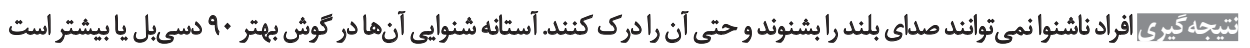

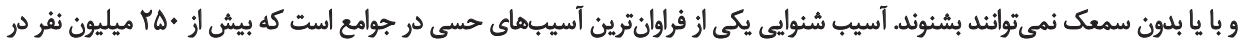

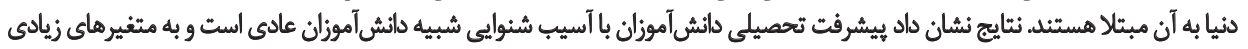

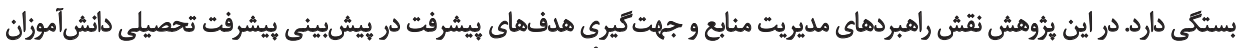

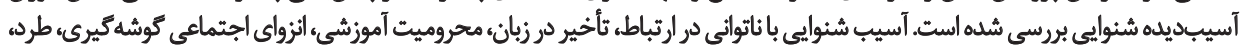

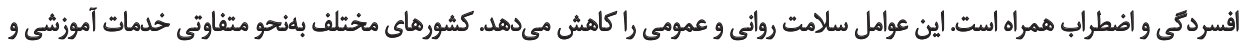

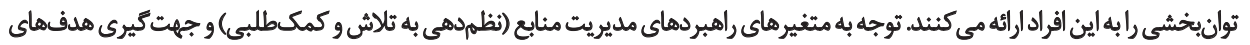

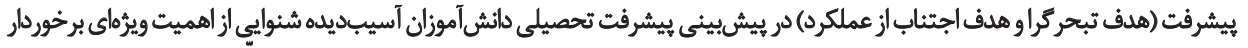

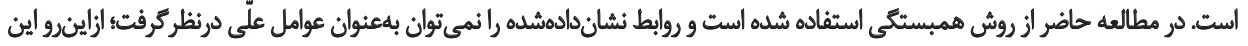

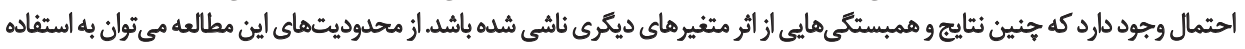

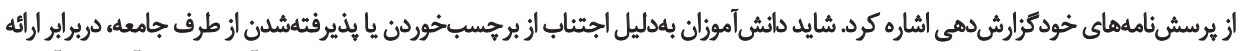

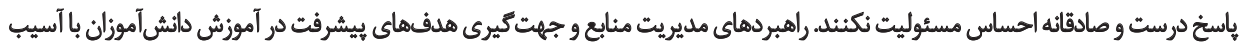

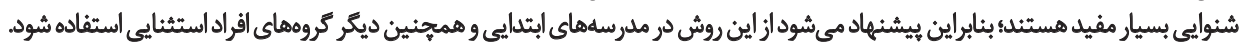

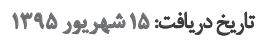

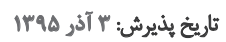

كليدوازوها:

راهبردهاى مديريت

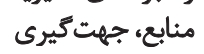

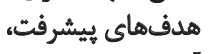
آسيبشنوايى 
زاست. سازه راهبردهاي مديريت منابع شامل مقياس هاي ملديريت

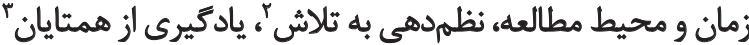

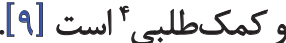

مديريت زمان و مكان مطالعه، يعنى داتشآموزان بايد زمان

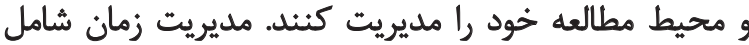

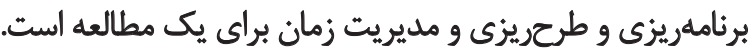

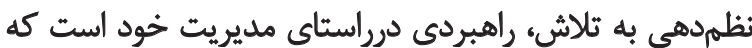

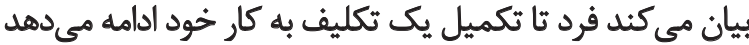

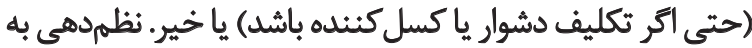

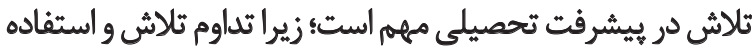

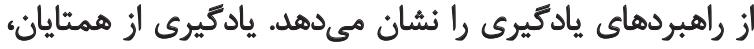

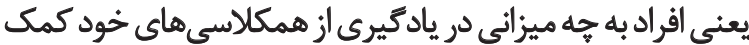

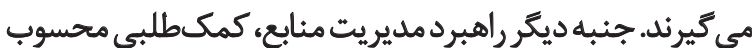

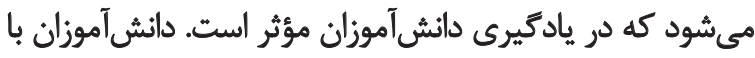

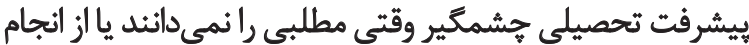

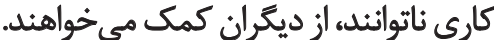

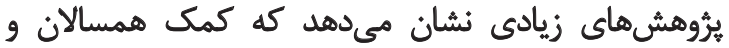

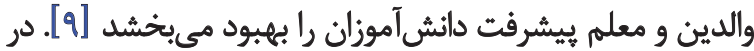

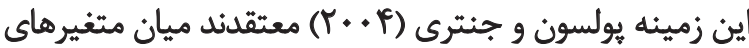

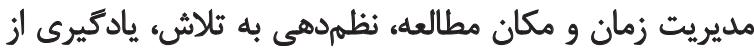

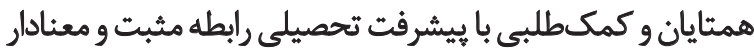

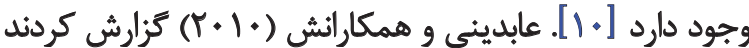
ياد

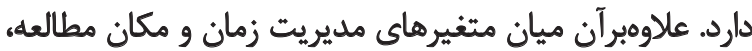

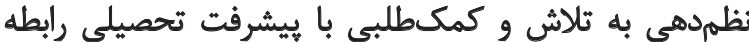

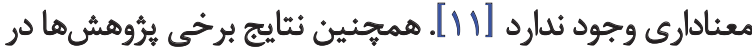

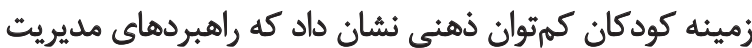

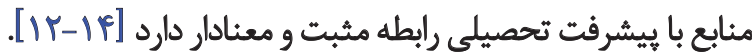
علاومبر راهبردهاى مديريت منابع كه سهم عمده و تأثير كذارى

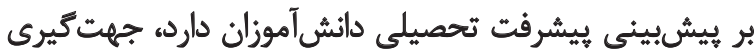

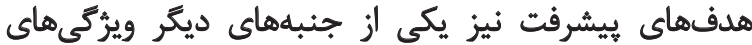

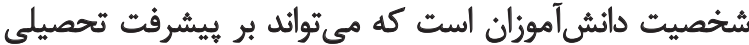

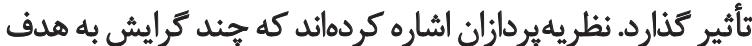

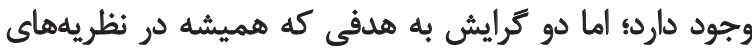

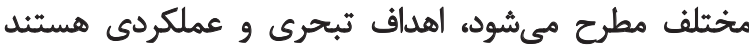

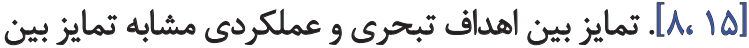

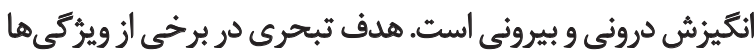

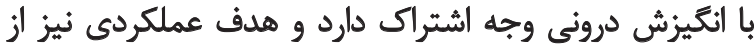
جهاتى شبيه جنبههاى خاصى از انكيزش بيرونى است.

\section{Effort regulation}

3. Peer learning

4. Help seeking
مقلمه

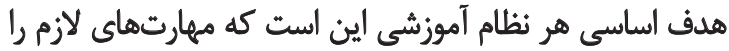

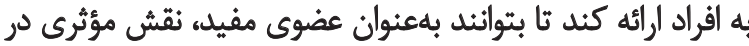

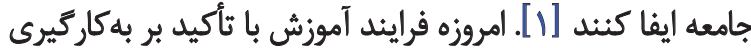

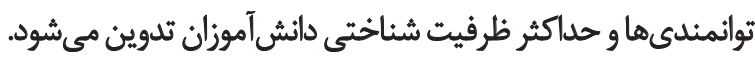

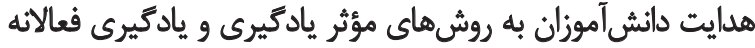

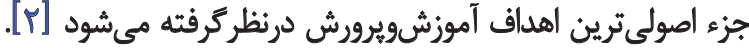

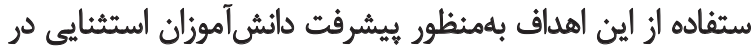
امور تحصيلى بسيار بالهميت است.

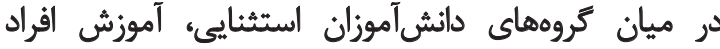

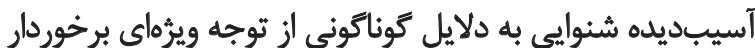

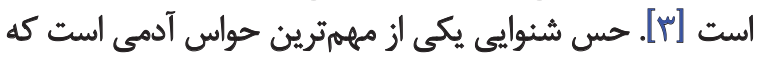

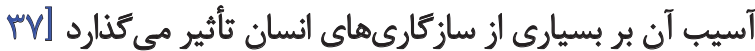

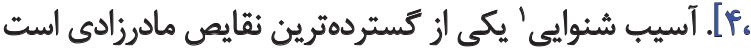

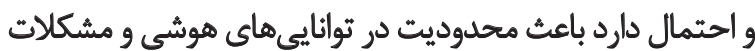

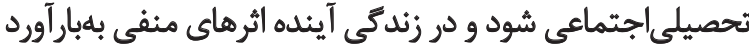

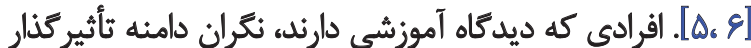

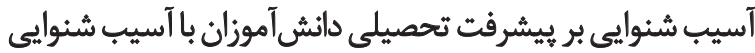

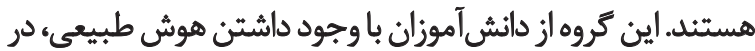

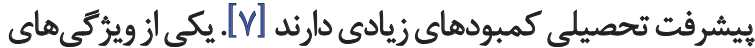

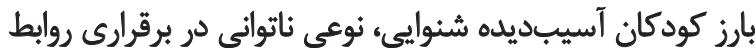

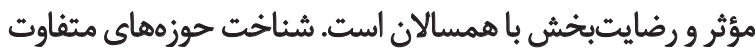

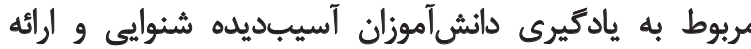

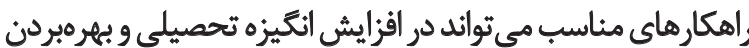

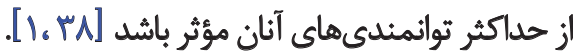

تعدادى از مطالعات نشان داده است كه رابطه هوش و

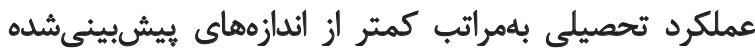

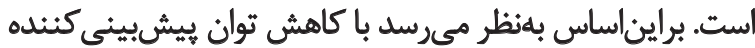

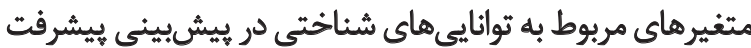

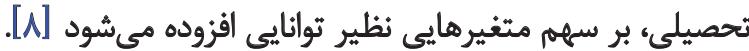

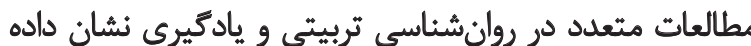

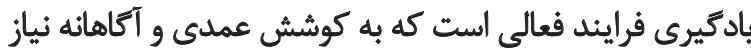

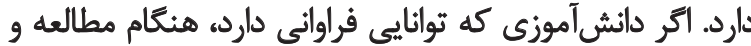

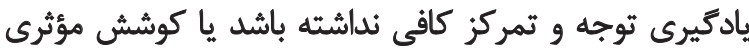

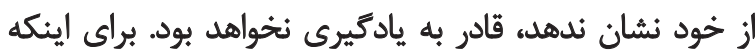

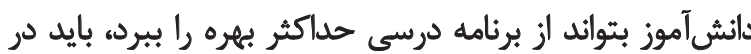

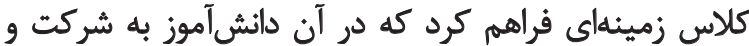

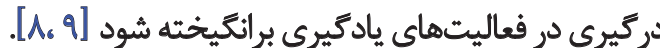
يكى از عوامل مؤثر بر بيشرفت تحصيلى بر هايه مدل نظرى

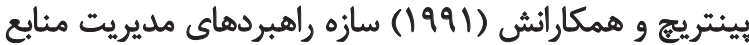

1. Hearing impairment 


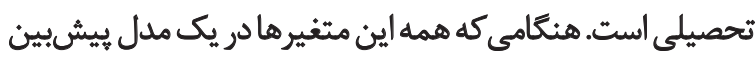

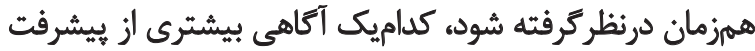

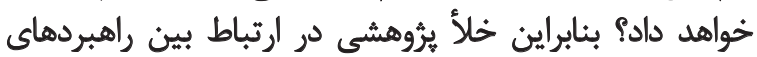

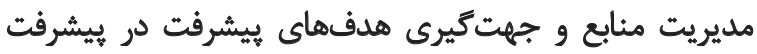

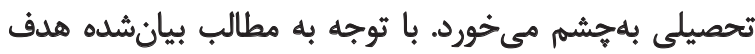

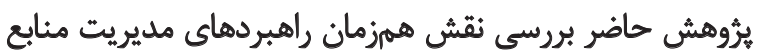

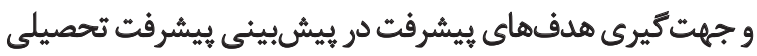

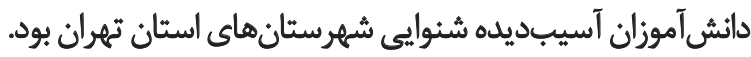

$$
\text { ورش بروسى }
$$

مطالعه حاضر، مطالعهاي توصيفىتحليلى از نوع همبستكى إنى إنى

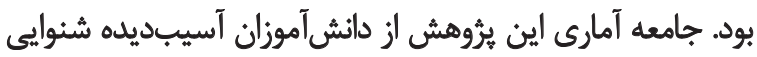

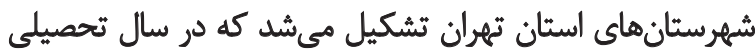

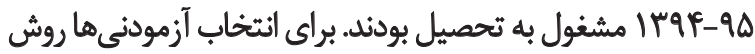

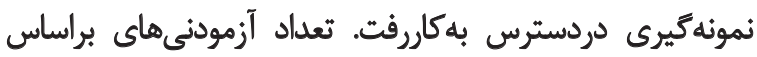

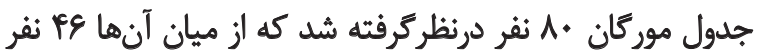

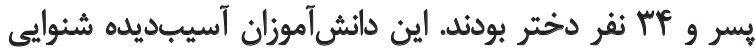

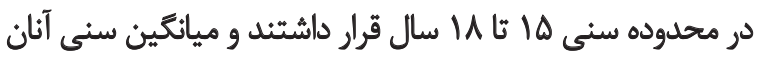

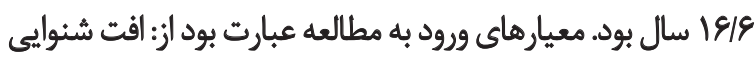

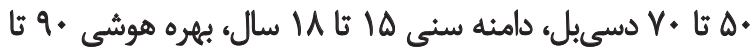

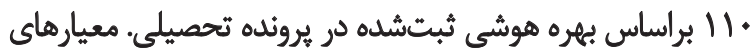

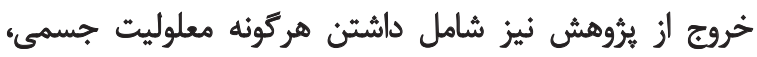

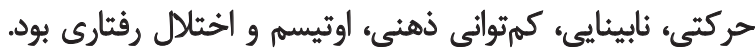

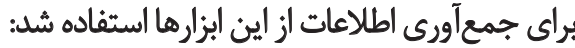

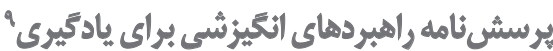

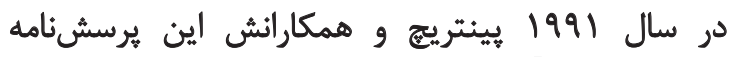

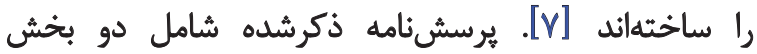

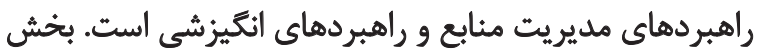

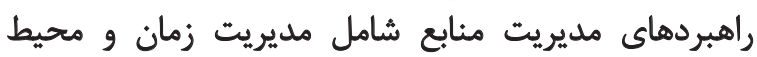

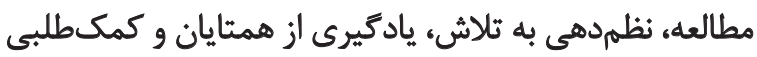

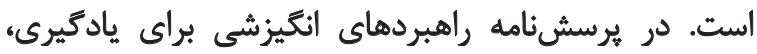

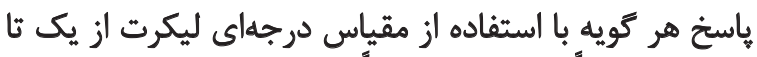

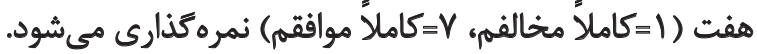

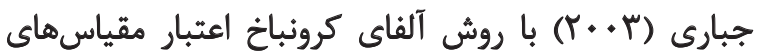

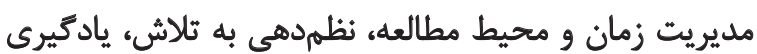

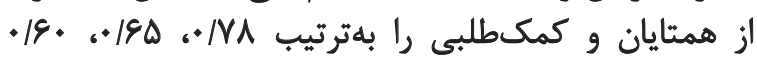

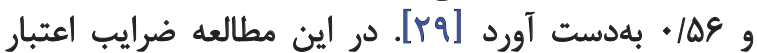

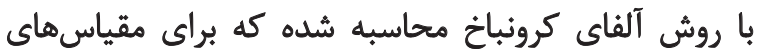

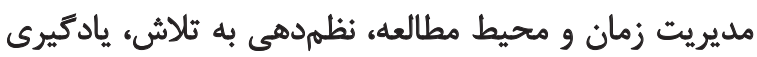

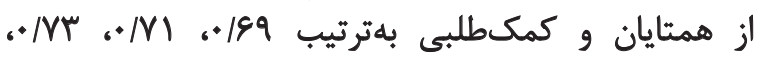

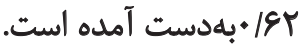

9. Motivational Strategies for Learning Questionnaire (MSLQ)

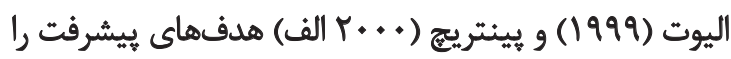

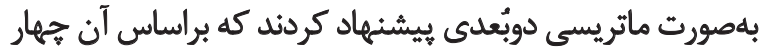

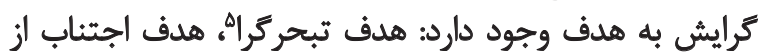

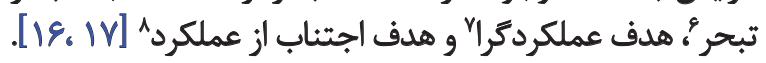

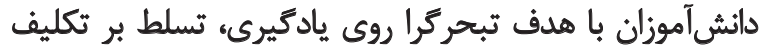

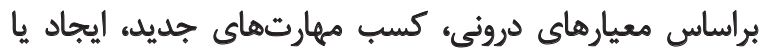

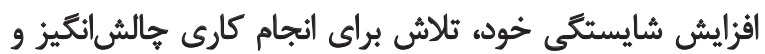

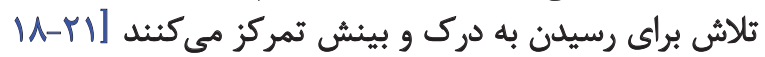

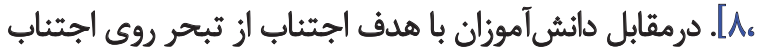

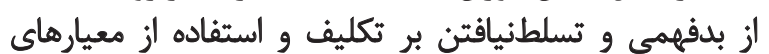

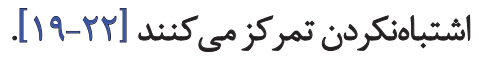

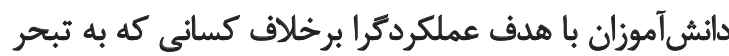

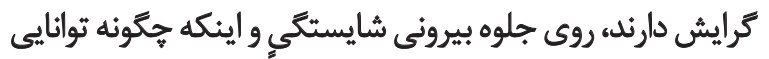

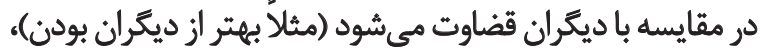

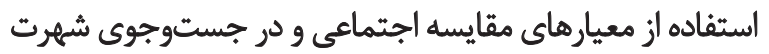

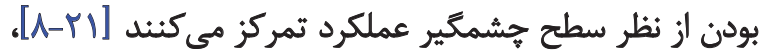

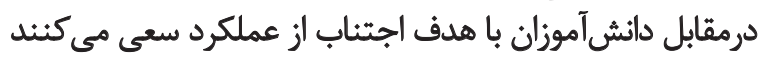

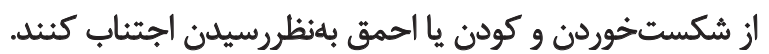

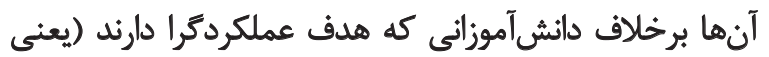

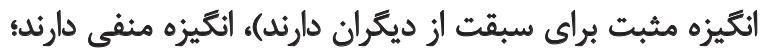

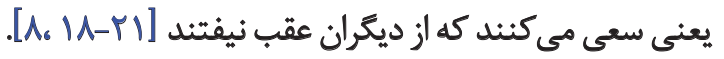

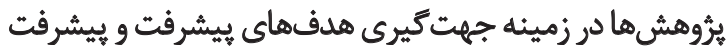

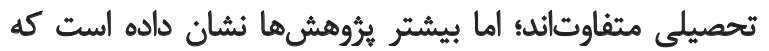

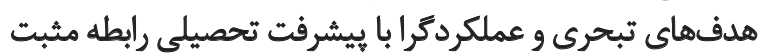

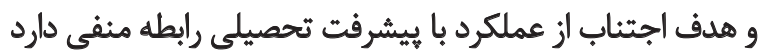

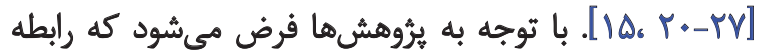

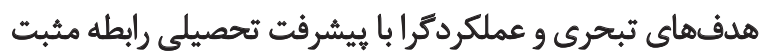

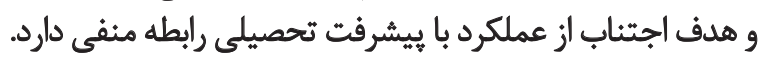

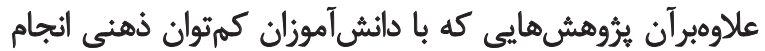

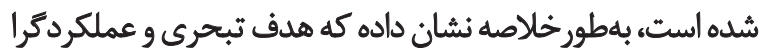

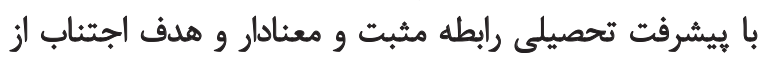

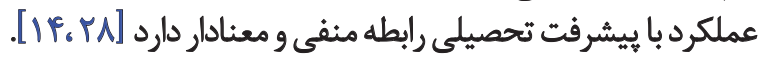
در مطالعات بسيارى نقش راهبردهاى مديريت منابع و و

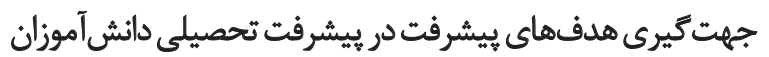

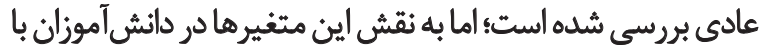

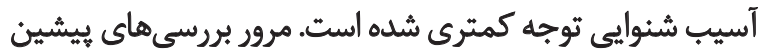

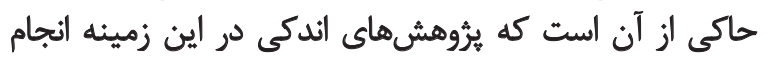

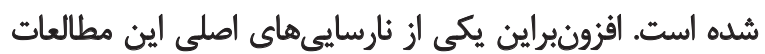

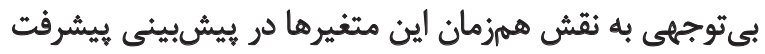

5. Mastery-approach goal

6. Mastery-avoidance goal

7. Performance-approach goal

8. Performance-avoidance goal 
رعايت نكات اخلاقى يُؤوهش از والدين دانشآموزان شركت كنيده در

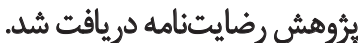

در مرحله بعد يس از جلب همكاري دانش آموزانء يرسشنامهنها

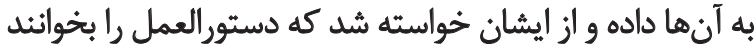

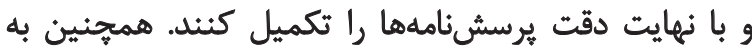

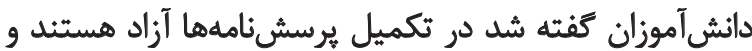

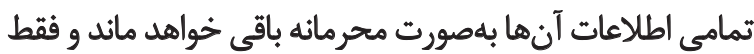

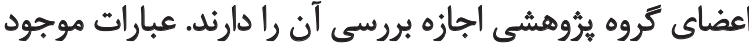

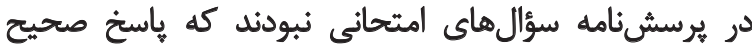

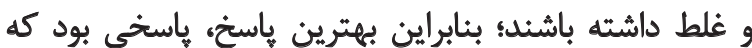
وضعيت واقعى دانشآموزان رانشان مين بنداد.

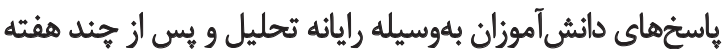

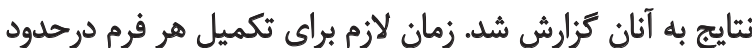

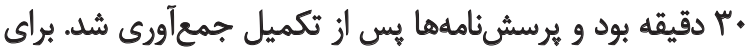

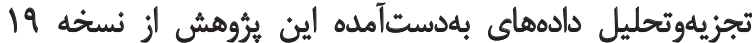

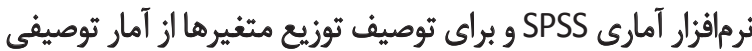

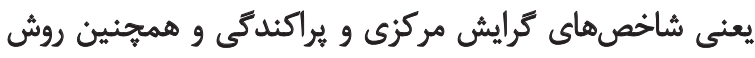
ركرسيون كامبه كام استفاده شد.

يافتهها

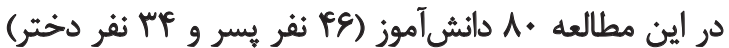

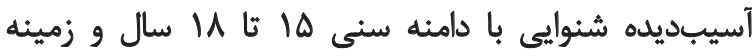

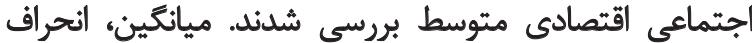

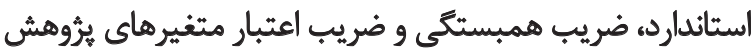

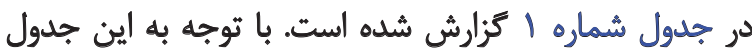

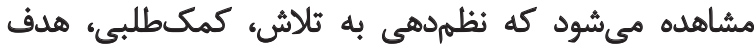
تبحركرا و هدف اجتناب از عملكرد با بيشرفت تحصيلى رابطه

\section{يرسش نامه تجديدنظرشده جهت كيرى هلدفهاى بيشرفت 1"}

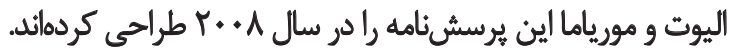

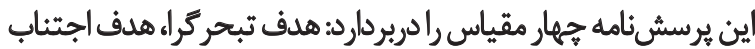

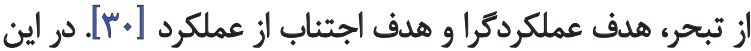

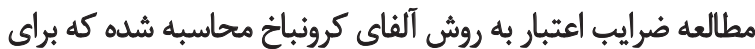

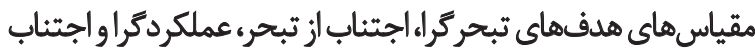

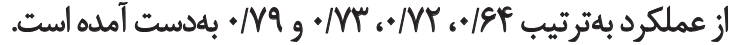

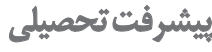

ميانكين نمرات نوبت اول دانشآموزان در درسهاي علوم تجربى

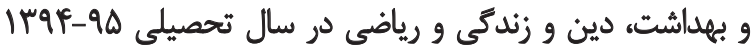

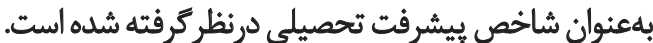

$$
\text { روشّ اجمرا }
$$

در مرحله مقدماتى دو يرسشنامه راهبردهاى انكيزشى براى

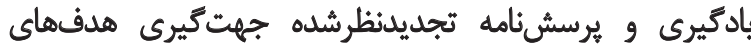

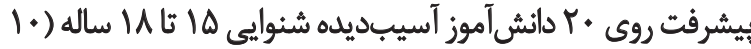

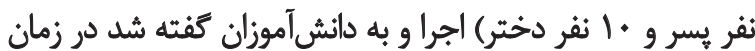

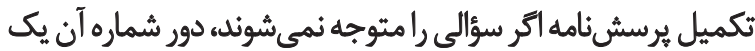

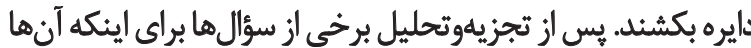

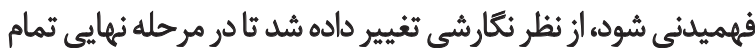

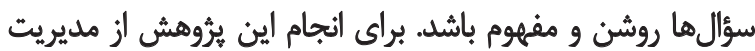

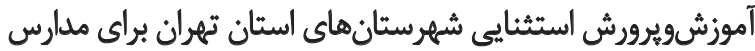

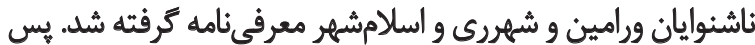

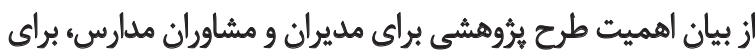

10. Achievement Goals Questionnaire-Revised (AGQ-R)

\begin{tabular}{|c|c|c|c|c|c|c|c|c|c|c|c|}
\hline 9 & $\Lambda$ & $\checkmark$ & 8 & $\Delta$ & f & $r$ & $r$ & 1 & SD & M & متغير \\
\hline & & & & & & & &.$/ 99$ & Ver & $r / P A$ & ا. مديريت زمان و محيط مطالعه \\
\hline & & & & & & & $\cdot M$ & $\cdot / r 1^{*}$ & INA & $F / M$ & Y. نظهمدهى به ثالاش \\
\hline & & & & & & $\cdot M r$ & .1 .9 & $\% 1$ & 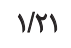 & Y.8 & "ا. يادكيرى از همتايان \\
\hline & & & & & . & $+/ 19^{\circ}$ & $\cdot / 1 r^{*}$ & -.1 .8 & $\cdot / 19$ & $\Delta / 91$ & F. \\
\hline & & & & /at & $\% .8$ &.$/ N \mu^{*}$ & 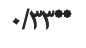 &.$/ m e *$ &.$/ 9 V$ & $9 / \pi$ & هـ هدف تبحرك, \\
\hline & & & $\cdot / N$ &.$/ 1 \Lambda^{* *}$ & $\% 1$ & $+/ 10^{\circ}$ & $\cdot / \pi$ & . TeEn & V/at & $P / A H$ & و هلف اجتناب از تبحر \\
\hline & & $+M$ & ( &.$/ \mathrm{A}^{* *}$ & 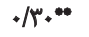 & $\cdot \pi \Lambda^{* *}$ & $* / 79 * *$ & $+/ 19^{*}$ & V/at & $\Delta / 19$ & Y. هدف عملكرد5ر1 \\
\hline & $\bullet / M 9$ & . & $+(\Delta)^{* *}$ & $-* \%+r$ & $-+1+\Delta$ &.$/ 19^{*}$ &.$M \mathrm{~A}^{\circ}$ & $* M r^{*}$ & $1 / \% 0$ & $r / \varphi^{\prime \prime}$ & ᄉ هذف اجتيناب از عملكرد \\
\hline$\cdot M$ & $. / M=$ & $.119^{\circ}$ &.$- / 10$ &.$/ \Delta N^{* *}$ &.$/ M e * *$ & 1.9 & $. / 4+40$ & $.1+1$ & $P / M$ & IENT & 9. بيشرفت تحصيلى \\
\hline
\end{tabular}

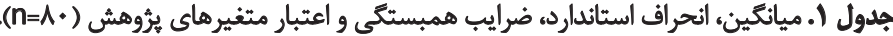


جدول T. خحلاصه تحليل ركرسيون با مدل كامبه كام.

\begin{tabular}{|c|c|c|c|c|c|c|c|c|}
\hline الجتمال & dft & df) & $\mathbf{F}$ & 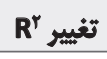 & $\mathbf{R}^{r}$ & $\mathbf{R}$ & هتغير ييشيين & مدل \\
\hline $.1 . .1$ & $\mathrm{VA}$ & 1 & $F q / r V$ & ( & ( ) & $.1 \Delta 1$ & هدف تبحركرا & 1 \\
\hline $.1 . .1$ & Wr & 1 & $|V| \cdot \Delta$ & .1 .99 & - /erta & .189 & هدف تبحركرا و نظمهدهى به تلاش & r \\
\hline $.1 \cdot . r$ & ve & 1 & $1.18 \mathrm{~F}$ & .1 .89 & $\cdot 10 \cdot f$ & $\cdot M$ & هدف تبحركرا و نظمردهى به تثلاش و كمكطلبى & $r$ \\
\hline$\% \bullet \Delta$ & VQ & 1 & $\Delta / \& q$ & $\cdot / T A$ & . IArT & $\cdot M r$ & هدف تبحركرا و نظمهدهى به تملاش و كمكرطلبى و هدف اجتناب از & $f$ \\
\hline
\end{tabular}

جدول "ا. ضرايب استاندارد و غيراستاندارد و همبستكي تفكيكى و نيمهتفكيكي متغيرها در معادله ركرسيون با مدل كامبه كام.

\begin{tabular}{|c|c|c|c|c|c|c|c|}
\hline \multicolumn{3}{|c|}{ همبستكى } & \multirow{2}{*}{ مقدار اهتمال } & \multicolumn{2}{|c|}{ ضرايب رترسيون } & \multirow{2}{*}{ مثغير ييشبين } & \multirow{2}{*}{ مدل } \\
\hline ثيمهتفكيكى & تفكيكى & صفر مرتبه & & B استائدارد شده B & غير استائدارد b & & \\
\hline $.10 \mathrm{~A}$ &.$/ M A$ &.$/ 101$ & $.1 .+1$ &.$/ 1 M$ & $1 / 1$. & هدف تبحركرا & 1 \\
\hline .198 &.$/ 89$ &.$/ M A$ & .1 .01 & .181 & $V / M$ & هلف تبحركرا & \\
\hline.$/ \pi$ &.$/ T V$ & / & $.1 . .1$ & . &.$/ 90$ & نظمددهى به تلاش & 1 \\
\hline.$/ a F$ &.$/ \Delta Y$ &.$/ A 1$ & $.1 .+1$ & $.1 \Delta \Delta$ & $\mathrm{l} / \mathrm{v}$ & هدف تبحركرا & \\
\hline.$/ 40$ &.$/ 7 q$ & . & $.1+\infty 1$ &.$/ 4 F$ &.$/ 99$ & نظمردهي به تثلاش & $r$ \\
\hline.$/ T \Delta$ & $+\pi$ & $+/ \pi$ & $*+* r$ &.$/ \pi$ & $+/ A r$ & كمكسلبي & \\
\hline . &.$/ \Delta \Delta$ &.$/ 141$ & $.1+1$ & . IOF & V/aT & هدف تبحركرا & \\
\hline . & . & . $/ 4$ & $+\infty 1$ &.$/ 4 T$ & . & نظهمدهى به تالاش & \\
\hline.$/ M$ &.$/ r V$ &.$M r$ & $\mathscr{H}$ & M &.$/ N E$ & كمكطلبيى & 1 \\
\hline r &.$/ 10$ & . & 100 & $.11 F$ & . & هلف اجتناب از عملكرد & \\
\hline
\end{tabular}

از تغييرات ييشرفت تحصيلى را ييشبينى كند. در مدل دوم يس از

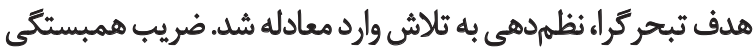

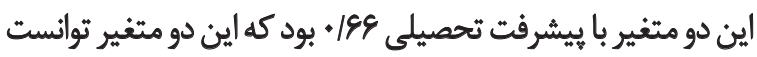

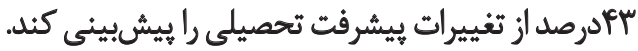

ورود متغير وظيفهشناسى نيز توان بيشبينى را وا 9 درصد

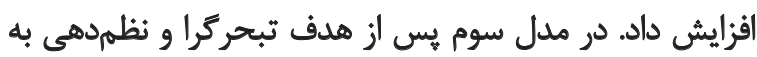

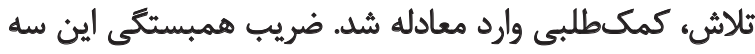
متغير با ييشرفت تحصيلى

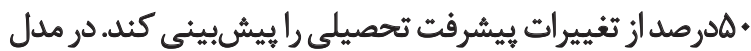

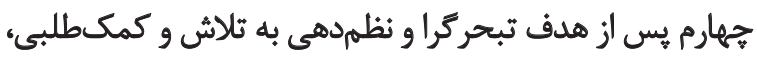

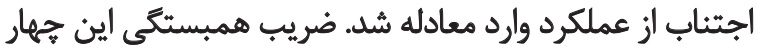

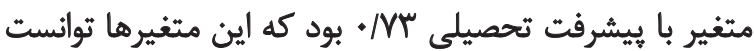

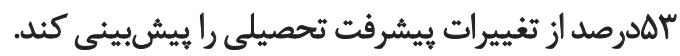

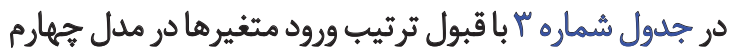
مقياسهاى هدف تبحركرا، نظمدهى به تثلاشي، كمكسطلبى و و
مثبت و معنادار دارد؛ اما متغيرهاى ديكًر با بيشرفت تحصيلى

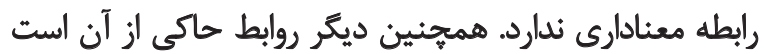

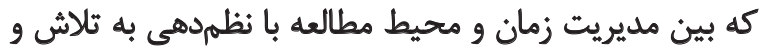

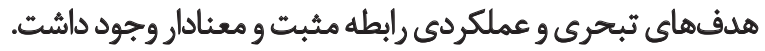

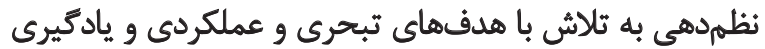

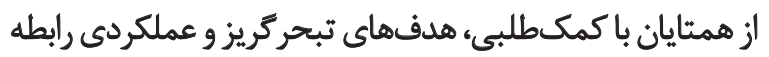

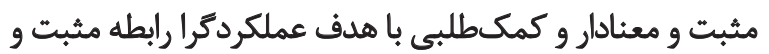

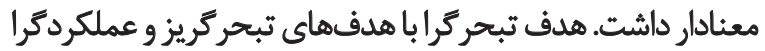
رابطه مثبت و معنادار داشت. براي بيشبينى بيشرفت تحصيلى دانشآموزان از آزمون آمارى

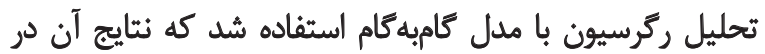

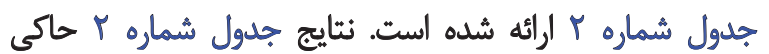

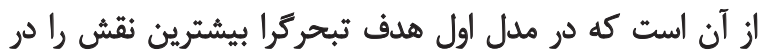

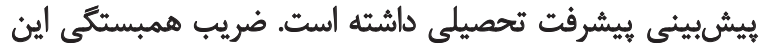

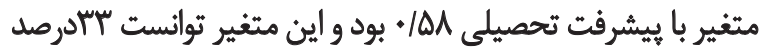




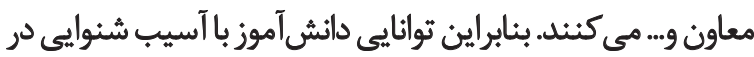

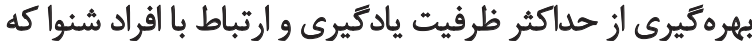

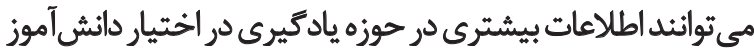
قرار دهنده در عملكرد تحصيلى آنان تأثير بهترى خوانديرى خواهد داشت

از ميان هدفهاى بيشرفت، هدف تبحركرا و هدف اجتناب از

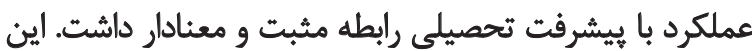

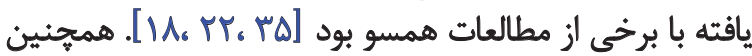

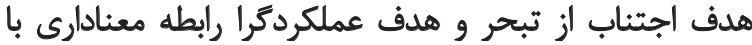

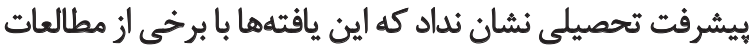

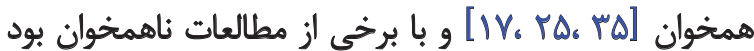

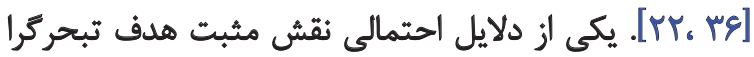

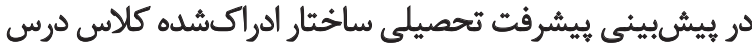

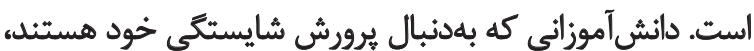
بهدليل تلاشهايشان ييشرفت جشمكيرى مي كنيند.

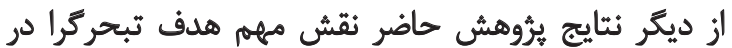

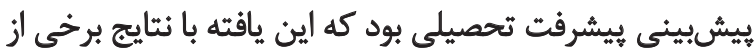

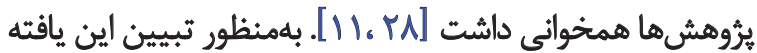

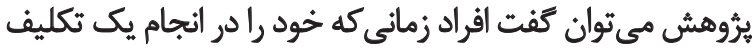

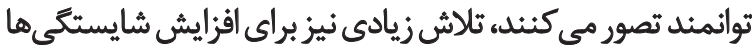

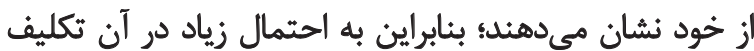

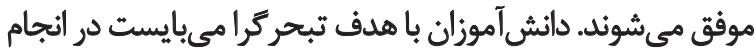

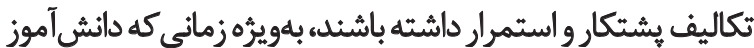

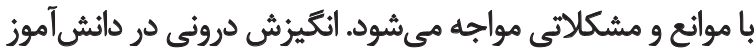

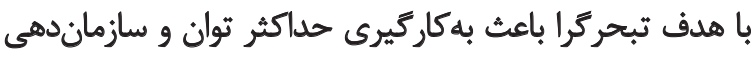

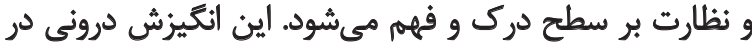

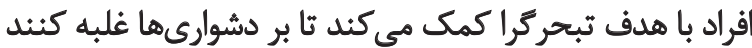

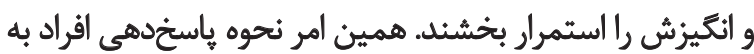

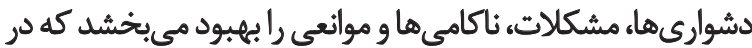

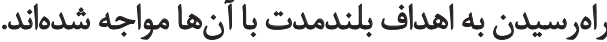

در اين مطالعه مشخص شد در مدلى كه راهبردهاى مديريت

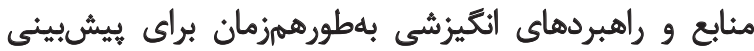

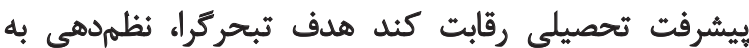

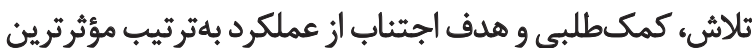

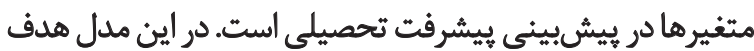

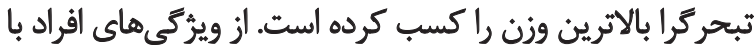

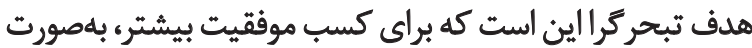

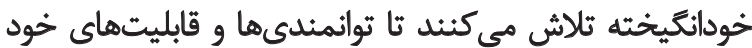

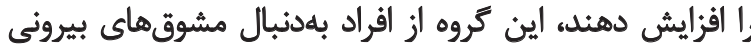

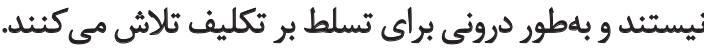
مى توان نتيجه كرفت دربين متغيرهاي كوناكونى كهد بر بيشرفت

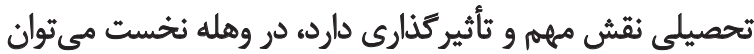
انكَيزش درونى و انتظارات فرد را نام برد. منظور از انتظارات و واتئ

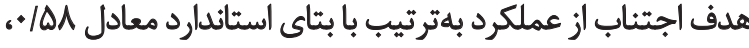

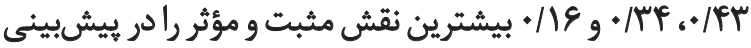
بيشرفت تحصيلى دارد.

بحث

برثوهش حاضر در دانشآموزان آسيبديده شنوايى با دامنه

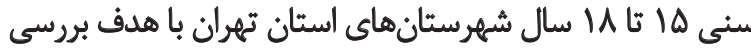

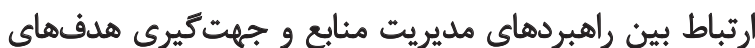

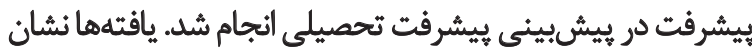

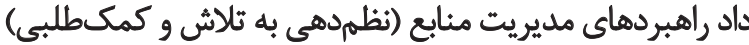

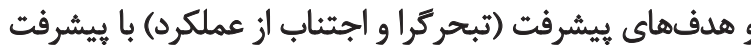

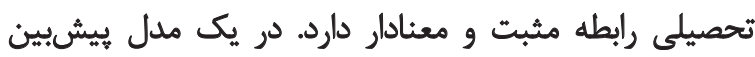

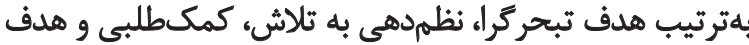

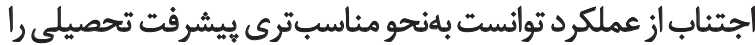

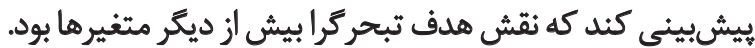
از ميان راهبردهاى مديريت منابع و نظهدهى به به تلاش و

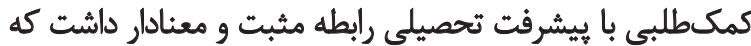

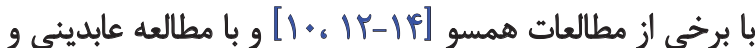

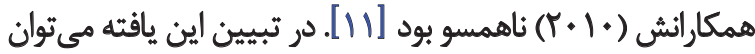

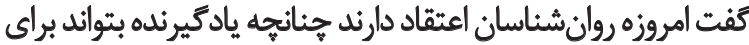

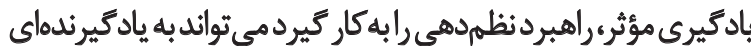

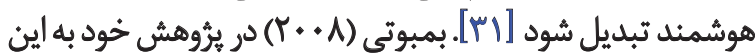

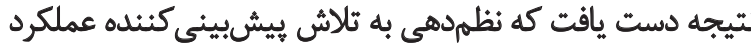

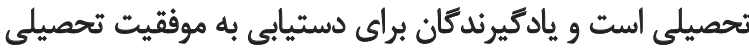

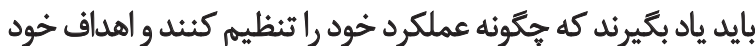

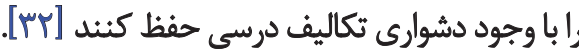
مطالعات بسيارى در حيطه آموزش و يادئيرى انجام شده

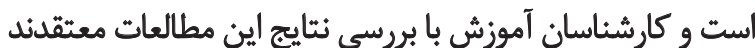

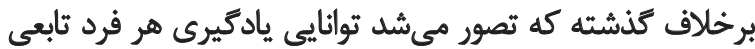

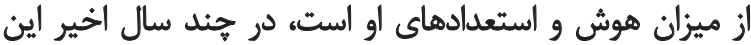

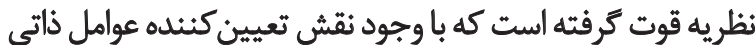

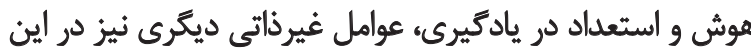

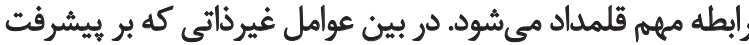

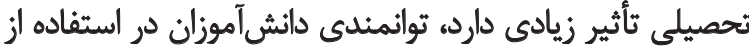

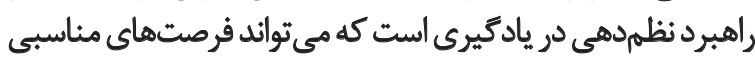
براى افزايش انكيزه و كارايى تحصيلى فراهم كند [آس، آس].

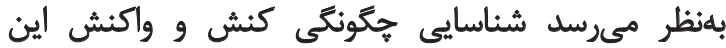

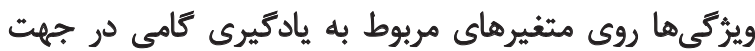

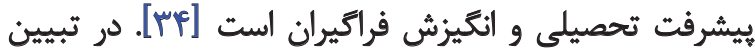

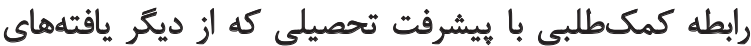

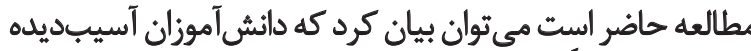

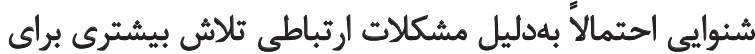

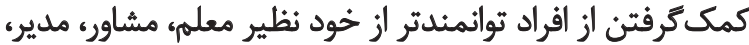




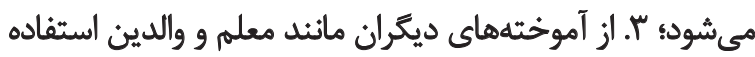

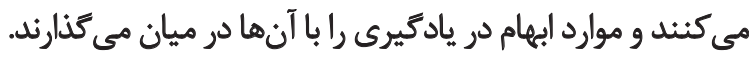

محدوديتها

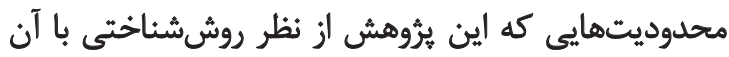

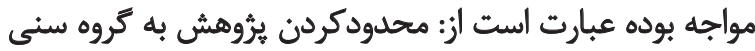

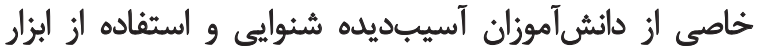

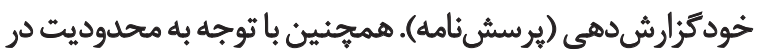

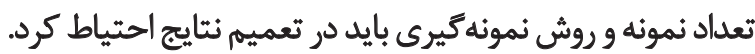

\section{يويشنهادها}

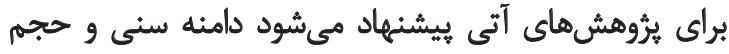

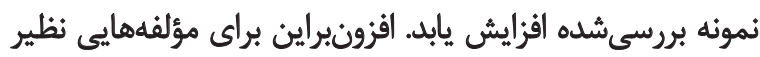

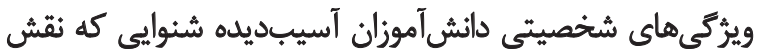

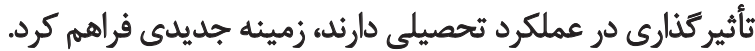

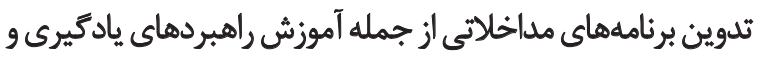

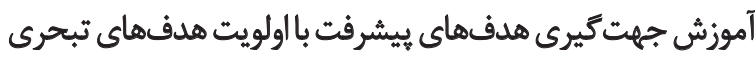

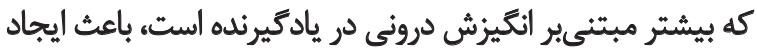

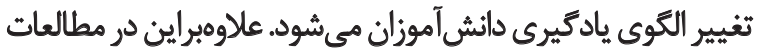

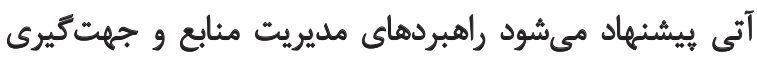

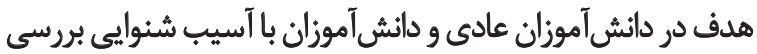

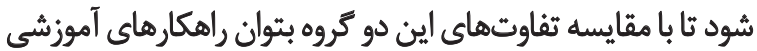

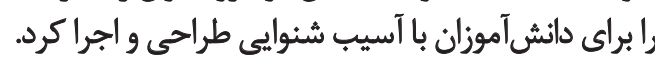

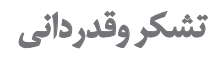

اين مقاله حاصل يك فعاليت بثروهشى در مقطع دكترى است.
انكيزش درونى، يعنى تصور اينكه فرد خود رادر برخورد با با تكليف برديف

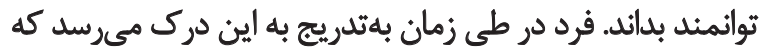

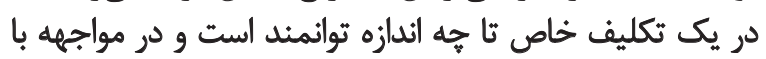

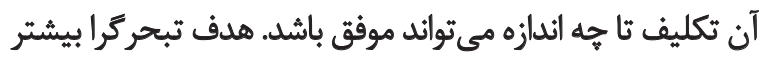

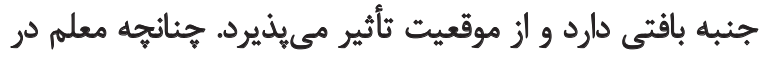

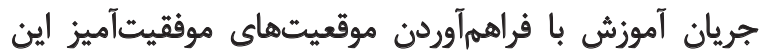

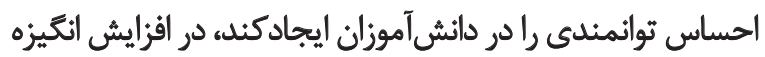

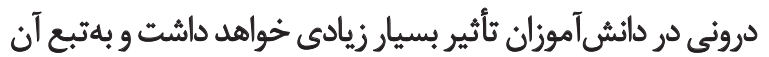
عملكرد بهترى در تحصيل دانشآموز ايجاد خواهد كردي

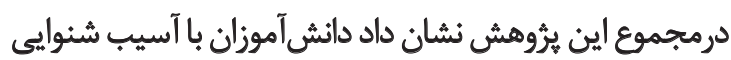

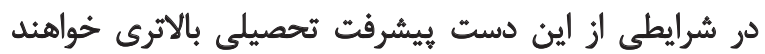

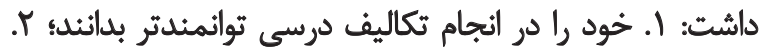

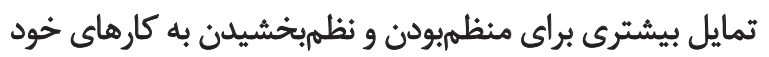

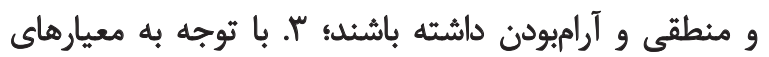

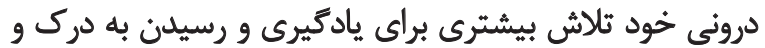

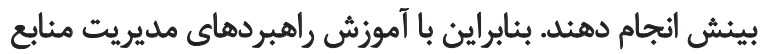

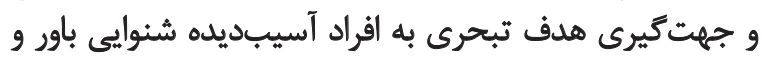

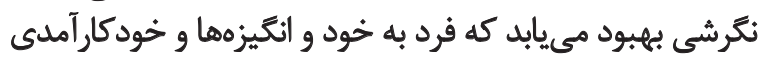

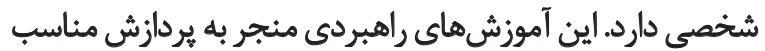

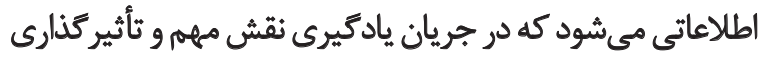

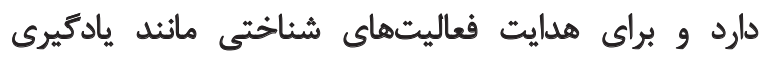

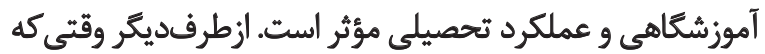

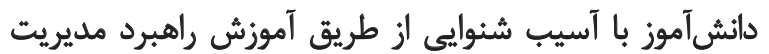

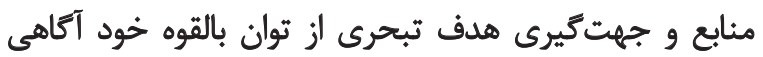

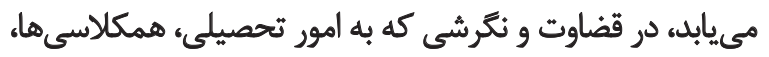

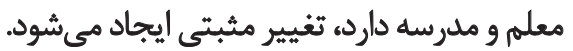

\section{نتيجلتيرى}

بيشرفت تحصيلى دانشآموزان آسيبديده شنوايى همانيد

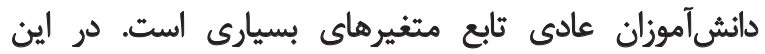

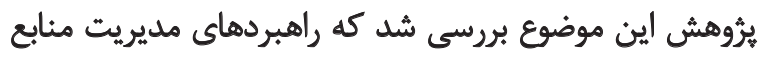

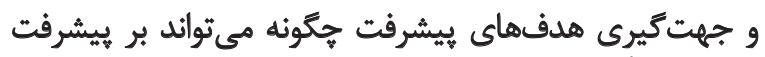

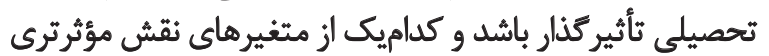

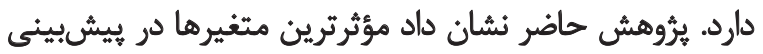

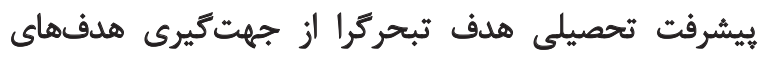

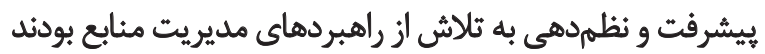

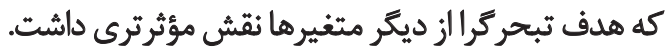

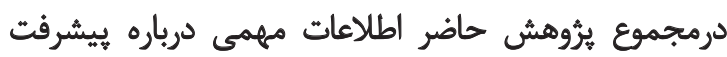

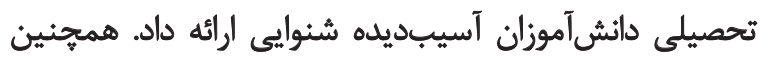

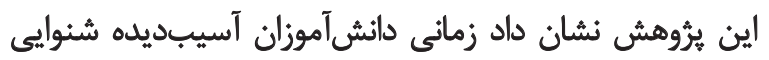

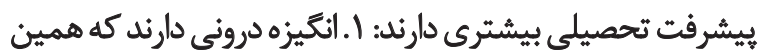

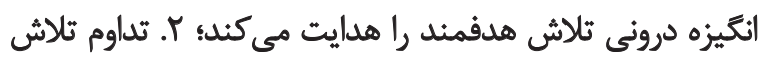

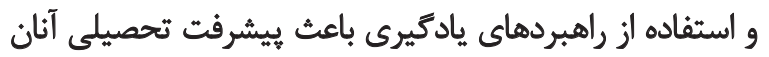




\section{References}

[1] Ashouri M, Jalil-Abkenar SS, Hasanzadeh S, Pourmohamadreza Tajrishi M. [Speech intelligibility in children with cochlear imb plant, with hearing aids and normal hearing (Persian)]. Journal of Rehabilitation. 2013; 14(3):8-15.

[2] Pourmohamadreza Tajrishi M, Ashori M, Jalil-Abkenar SS, Ashoori J. The relationship among personality factors, motivational strategies and achievement goals orientation in predicting academic achievement of the students with intellectual disability. Iranian Rehabilitation Journal. 2011; 14:32-38.

[3] Hardman M, Drew C, Egan W. Human Exceptionality: school, community, and family $[$ H. Alizadeh, K. Gangi, M. Yousefi, Looyeh, F. Yadegari, Persian trans]. $7^{\text {th }}$ ed. Tehran: Danzheh Publication; 2007.

[4] Movallali G, Jalil-Abkenar SS, Ashori M. [The efficacy of group play therapy on the social skills of pre-school hearing-impaired children (Persian)]. Journal of Rehabilitation. 2015; 16(1):18-27.

[5] Caldarella P, Merrell KW. Common dimensions of social skills of children and adolescents: Taxonomy of positive behaviors. School Psychology Review. 2008; 26: 264-78.

[6] Movallali G, Parhon K, Daneshmandan N. [Lip reading and speech perception of hearing impaired students in special schools for the deaf in Tehran (Persian)]. Journal of Rehabilitation. 2013; $14(2): 29-37$.

[7] Ashouri M, Jalili-Abkenar SS, Pourmohamadreza-Tajrishi M. [Investigation of the efficacy of emotional intelligence training on the self-esteem in boy students suffering from hearing loss (Persian)]. Journal of Rehabilitation. 2014; 15:3-12.

[8] Furnham A, Chamorro-Premuzic T, McDougall F. Personality, cognitive ability, and beliefs about intelligence as predictors of academic performance. Journal of Learning and Individual Differences. 2003; 14(1):47-64. doi: 10.1016/j.lindif.2003.08.002

[9] Pintrich PR, Smith DA, Garcia T, Mc Keachie W. Reliability and predictive validity of the Motivated Strategies for Learning Questionnaire (MSLQ). Educational \& Psychological Measurement. 1993; 53(3):801-13. doi: 10.1177/0013164493053003024

[10] Paulsen MB, Gentry JA. Motivation, learning strategies, and academic performance: A study of the college finance classroom. Journal of Financial Practice \& Education. 2004; 6(1):78-89. doi: 10.4324/9781410610225

[11] Abedini Y, Bagherian R, Sadat Kadkhodaie M. [The relation among motivational beliefs, cognitive and metacognitive strategies and academic achievement: Testing of alternative models (Persian)]. Journal of Advances in Cognitive Science. 2010; 12(3):34-48

[12] Van-reusen-Anthony K. Cognitive and metacognitive intervention important for teacher of students with mental retardation. American Journal of Mentally Deficiency. 1994; 25(2):53-62.

[13] Mettler R. Cognitive basis for teaching of children with mental retardation. American Journal of Mentally Deficiency. 1994; $19(2): 33-45$

[14] William M, Holy K. Model for improving science teaching for students with intellectual disability. Journal of Intellect Disable Research. 2005; 26(2):25-37.
[15] Elliot AJ, Dweck CS. Goals: an approach to motivation and achievement. Journal of Personality \& Social Psychology. 1988; 54(1):5-12. PMID: 3346808

[16] Elliot AJ. Approach and avoidance motivation and achievement goals. Journal of Educational Psychologist. 1999; 34(5):169-89.

[17] Pintrich PR. An achievement goal theory perspective on issues in motivation terminology, theory, and research. Journal of Contemporary Educational Psychology. 2000; 25:92-104. doi: doi: 10.1006/ceps.1999.1017

[18] Midgley C, Kaplan A, Middleton M, Maehr UT, Anderman EM, Anderman LH, et al. The development and validation of scales assessing student's achievement goal orientations. Journal of Contemporary Educational Psychology. 1998; 23:113-31.

[19] Bong M. Age-relate differences in achievement goal differentiation. Journal of Educational Psychology. 2009; 104:879-96. doi: $10.1037 / \mathrm{a} 0015945$

[20] Luo W, Hogam D, Paris SG. Predicting Singapore student's achievement goals in their English study: Self-Construal and classroom goal structure. Journal of Learning and Individual Differences. 2011; 21(5):526-35. doi: 10.1016/j.lindif.2011.07.002

[21] Dickhauser C, Buch S, Dickhauser O. Achievement after failure: The role of achievement goals and negative self-related thoughts. Journal of Learning and Instruction. 2011; 21(1):152-62. doi: 10.1016/j.learninstruc.2010.01.002

[22] Elliot AJ, Mc Gregor H. A 2×2 achievement goal framework. Journal of Personality and Social Psychology. 2001; 80(3):501-19. doi: 10.1037/0022-3514.80.3.501

[23] Church MA, Elliot AJ, Gable SL. Perception of classroom environment achievement goals, and achievement outcomes. Journal of Educational Psychology. 2001; 93(1):43-54. doi: 10.1037/0022-0663.93.1.43

[24] Pintrich PR, Conley AMA, Kempler TM. Current issues in achievement goal theory and research. International Journal of Educational Research. 2003; 39(4-5): 319-37. doi: 10.1016/j. ijer.2004.06.002

[25] Wolters CA. Advancing achievement goal theory: using goal, structures and goal orientation to predict student motivation, cognition and achievement. Journal of Educational Psychology. 2004; 96(2):236-50. doi: 10.1037/0022-0663.96.2.236

[26] Mouis KR, Edwards O. Examinig the stability of achievement goal orientation. Journal of Cotemporary Educational Psychology. 2009; 34(4):265-77. doi: 10.1016/j.cedpsych.2009.06.003

[27] Hanchon TA. The relation between perfectionism and achievement goals. Journal of Personality and Individual Differences. 2010; 49(8):885-90. doi 10.1016/j.paid.2010.07.023

[28] Swalender L, Karin T. Influences of family based prerequisites, reading attitude and self-regulation on reading ability of student with intellectual disability. Journal of Intellect Disable Research. 2006; 32(2):206-30. doi: 10.1016/j.cedpsych.2006.01.002

[29] Hoseini-Nasab SD, Rameshe SMH. [The investigation relationship between self-regulated learning components with intelligence (Persian)]. Journal of Human \& Social Sciences. 2001; 2(1): 85-96. 
[30] Elliot AJ, Murayama K. On the measurement of achievement goals: critique illustration, and application. Journal of Educational Psychology. 2008; 100(3):613-28. doi: 10.1037/00220663.100.3.613

[31] Senar T. The Effects of Problem-Based Learning on Self-Regulated Learning Skills and the Variables Predictive of These Skills. Mediterranean Journal of Social Sciences. 2013; 4(14):297-302. doi: $10.5901 /$ mjss.2013.v4n14p297

[32] Bembenutty H. Self-regulation of learning and academic delay of grafication: Gender and ethnic difference among college students. Journal of Advanced Academics. 2008; 18(4):586-616.

[33] Zimmerman BJ, Schunk DH. Self-regulated learning and performance. In: BJ. Zimmerman, DH. Schunk eds. Handbook of Self-regulation of Learning and Performance. New York: Routledge; 2011.

[34] Beishuizen J, Steffens K. A conceptual framework for research on self-regulated learning. In: R. Carneiro, P. Lefrere, K. Steffens, KJ. Underwood eds. Self-regulated Learning in Technology Enhanced Learning Environments: A European Perspective. Rotterdam: Sense Publishers; 2011.

[35] Liem AD, Lau S, Nie Y. The role of self-efficacy, task value, and achievement goals in predicting learning strategies, task disengagement, peer relationship, and achievement outcome. Journal of Contemporary Educational Psychology. 2008; 33(4):486-512. doi: 10.1016/j.cedpsych.2007.08.001

[36] Skaalvik E. Self-enhancing and self-defeating ego orientation: Relations with task avoidance orientation, achievement, self-perceptions, and anxiety. Journal of Educational Psychology. 1997; 89(1):71-81. doi: 10.1037//0022-0663.89.1.71

[37] Teymouri R, Nematzadeh S, Gharib M, Daneshmandan N. The role of non-linguistic variables in production of complex linguistic structures by hearing-impaired children. Iranian Rehabilitation Journal. 2011; 9:8-15.

[38] Teymouri R, Daneshmandan N, Hemmati S, Soleimani F. Perception development of complex syntactic construction in children with hearing impairment . Iranian Rehabilitation Journal. 2014; 12(4):11-16. 